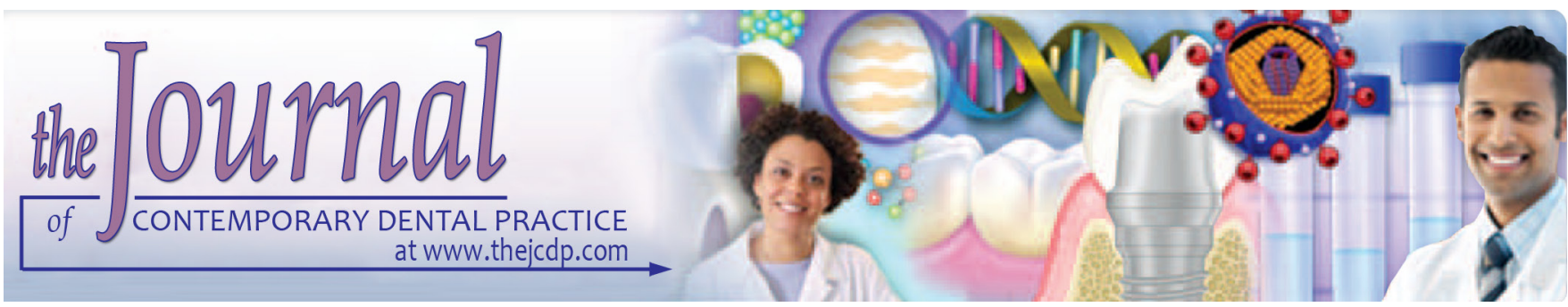

\title{
Incidence of Dentinal Root Defects Caused by RECIPROC Blue, ProTaper Gold, ProTaper NEXT and RECIPROC Nickel Titanium Rotary Instruments
}

\author{
${ }^{1}$ Salsabeil W Hussien, ${ }^{2}$ Hikmet A Al-Gharrawi
}

\begin{abstract}
Aim: This in vitro study was conducted to measure and compare the incidence of dentinal defects caused by (RECIPROC blue, ProTaper Gold, ProTaper NEXT and RECIPROC) nickel titanium (NiTi) rotary instruments.
\end{abstract}

Materials and methods: Seventy-five palatal roots of freshly extracted human maxillary first molars were used in this study. The total samples were randomly divided into five groups. Each group contained 15 samples $(\mathrm{N}=15)$ : group I: single file RECIPROC system, group II: ProTaper Next system, group III: ProTaper GOLD system, group IV: single file RECIPROC blue system and Group V: control group (No preparation). Root canal instrumentation were carried out according to manufacturer's instructions for each instrumentation system to \# 40 apical size. Each root sample was sectioned horizontally at $2 \mathrm{~mm}, 4.5 \mathrm{~mm}$ and $7 \mathrm{~mm}$, respectively from the apex. All root sections were observed under a stereomicroscope at 25X magnification.

Results: The roots prepared by Reciproc showed the highest incidence of dentinal defects followed by ProTaper NEXT, ProTaper Gold then RECIPROC blue group which showed the lowest incidence of dentinal defects. The data obtained were analyzed statistically using Fisher's exact test at or equal to $5 \%$ significance levels. Fisher's exact test revealed that RECIPROC groups had a significant difference when compared with RECIPROC blue $(p \leq 0.01)$ and with ProTaper Gold $(p \leq 0.05)$ groups. While, other comparisons between each pair of groups revealed a non-significant difference between groups $(p>0.05)$. Regarding dentinal defects at different levels (apical, middle, coronal), Fisher's exact test showed that there was a non-significant difference in the incidence of dentinal defects when comparing among different levels in the same group or when comparing among different groups at the same level $(p>0.05)$

\footnotetext{
1,2Department of Conservative Dentistry, Al-Mustansiriyah University/College of Dentistry, Baghdad, Iraq
}

Corresponding Author: Salsabeil W Hussien, Department of Conservative Dentistry Al-Mustansiriyah University/College of Dentistry, Baghdad, Iraq, Phone: +96407706148290, e-mail: salsabeilw.hussien@gmail.com
Conclusion: all experimental groups showed dentinal defects while no dentinal defects were observed in the negative control group.

Clinical significance: the potential of root fracture is reduced using more flexible $\mathrm{Ni}$ Ti rotary instruments.

Keywords: Dentinal defects, Fisher's exact test, ProTaper Gold,ProTaper Next, RECIPROC, RECIPROC blue.

How to cite this article: Hussien SW, Al-Gharrawi HA Incidence of Dentinal Root Defects Caused by RECIPROC Blue, ProTaper Gold, ProTaper NEXT and RECIPROC Nickel Titanium Rotary Instruments. J Contemp Dent Pract 2019;20(3):291-297.

Source of support: Nil

Conflict of interest: None

\section{INTRODUCTION}

Root canal instrumentation is accomplished using endodontic instruments and irrigating solutions under aseptic working conditions. Root canal instrumentation may be carried out using hand-held or engine-driven (rotary) instruments. ${ }^{1}$ Rotary NiTi based preparation became the mainstream approach to mechanically enlarge the root canal space, overcoming most of the conventional preparation drawbacks.

Nevertheless, an important concern has been raised and confirmed, namely the creation of dentinal defects due to motor-driven NiTi instrumentation. This situation is critical, considering the abundance in different designs, tapers, preparation protocols, number of files, and kinematics of the available NiTi systems. ${ }^{2}$

During and after root canal instrumentation, root canal wall can be harmed with the development of dentinal defects in the form of dentinal cracks or craze line which serve as localized sites of increased stress. With repeated stress from occlusal forces or when further clinical procedures are required such as post placement these dentinal defects may propagate in to vertical root fracture. ${ }^{3}$ 
Root cracks and fractures are two of the most frustrating aspects of endodontic and restorative dentistry. ${ }^{4}$ Vertical root fracture in endodontically treated teeth may lead to extraction of the tooth. ${ }^{5}$

Variation in NiTi instruments may result in different degrees of dentinal defects formation. ${ }^{6}$ Attempts had been made to develop better performing NiTi instruments included modifications in design features, mode of action, and heat treatment of the NiTi alloy. ${ }^{7}$ RECIPROC is a single-file reciprocating instrument that is able to completely prepare root canals with only single instruments. The file has an $\mathrm{S}$ shaped cross-section and manufactured using M-Wire NiTi alloy. ${ }^{8}$ RECIPROC was recently upgraded to RECIPROC blue file system designed with the same geometries as RECIPROC system. This was achieved by using special thermomechanical treatment that transforms the molecular structure of the alloy. This gives the RECIPROC blue file its characteristic blue color, increases the flexibility and resistance to cyclic fatigue and cause file to show less surface microhardness values compared with its predecessor, ${ }^{9}$ ProTaper Next shaping files have off-centered rectangular cross-sectional design. Progressive and regressive percentage tapers on a single file and manufactured using M-Wire NiTi alloy. ${ }^{10}$

ProTaper Gold system designed with identical architecture and operation as ProTaper Universal. However, ProTaper Gold have been developed with proprietary advanced metallurgy that provides increase in the flexibility and fatigue resistance of the files The metallurgical characteristics of ProTaper Gold files are similar to control memory (CM) wire. ${ }^{7}$

To the best of our knowledge, no study has been mentioned the incidence of dentinal defects after using RECIPROC blue, ProTaper Gold, ProTaper NEXT and RECIPROC Nickel Titanium Rotary instruments.

\section{MATERIALS AND METHODS}

Seventy-five freshly extracted human maxillary first molars were used in this study. The teeth extracted from patients their age ranges from (20-30). After extraction, the soft tissues on the tooth surface were removed manually with periodontal curette and stored in plastic containers contains $0.1 \%$ thymol solution (BDH chemical Ltd., England) at room temperature. The criteria for teeth selection included straight palatal root with no visible root caries, restoration, open apices, calculus, or anatomical irregularities. To standardize the palatal root length for all samples the root was sectioned at a length of $11 \mathrm{~mm}$ from anatomical apex using diamond disc by cutting off coronally perpendicular to the long axis of the root. Diagnostic radiographs were taken to confirm the existence of single straight canal, mature apex with no signs of internal resorption, calcification or pervious endodontic therapy. For all teeth, the canal width near the apex was compatible with a size $20 \mathrm{~K}$ file (Dentsply, Switzerland) and the root surfaces were verified for absence of any visible cracks or fractures using transmitted light (radii plus, Australia) and stereomicroscope (MEIJI Techno, Japan) at $12 \times$ magnification. The pulp tissue was extirpated using barbed broach followed by copious irrigation with $1 \%$ $\mathrm{NaOCl}$ then irrigation with $5 \mathrm{~mL}$ distilled water. Center location of the apical foramen and the patency of the canals were verified by insertion of size $15 \mathrm{~K}$-file into the root canal and advancing it until it visualized at the apical foramen. The correct WL was established by subtracting 1 $\mathrm{mm}$ from root length. Each root was wrapped with 2 layers of aluminum foil to provide space for saline soaked gauze to be wrapped around the root to keep the roots moist all the times during instrumentation. Impression material (putty and catalyst) (Major, Ormakit, Italy) were mixed according to the manufacturer's instructions and inserted inside the plastic tubes $(50 \mathrm{~mm}$ in height and $25 \mathrm{~mm}$ in diameter). The root was inserted in the center of putty material with the aid of dental surveyor (Dentaurum, Paraline) and the material was left to set. After setting of impression materials, the roots along with the aluminum foils were withdrawn from their simulated sockets and, the aluminum foils were removed from the root. The roots wrapped in a saline-socked gauze and reinserted again in its simulated socket in impression materials.

Samples were randomly divided into five groups, each group contain fifteen root samples. One group was left unprepared to serve as control group and the remaining four experimental groups were instrumented using RECIPROC blue (VDW, Germany), ProTaper Gold (Dentsply, Switzerland), ProTaper next (Dentsply, Switzerland), RECIPROC (VDW, Germany) Systems.

The sequences of root canal instrumentation used in this study were performed according to the manufacturer's instructions of the file system used in each group. All root canals were instrumented to MAF corresponding to \# 40 apical size. All files operated using electric speed and torque-controlled endodontic micromotor $X$ smart plus (Dentsply, Switzerland) which had a pre-programed setting to operate RECIPROC, RECIPROC blue, ProTaper GOLD and ProTaper NEXT instruments:

\section{Group I (RECIPROC System)}

Canal preparation was performed using RECIPROC R40 (40/0.06). R40 file inserted in the canal in a slow in-and-out pecking motion the amplitude of the in-and-out movements should not exceed $3 \mathrm{~mm}$, in-and out movement = 1 peck until the full WL had been reached. 


\section{Group II (ProTaper Next system)}

Canal preparation was performed by ProTaper NEXT rotary instruments at (speed: 300 Rpm and torque: 2.0 $\mathrm{Ncm})$. The instrumentation was completed in crown down manner using gentle in and out brushing motion. The instrumentation sequence was started as following: X1(17/04), X2 (25/06), X3 (30/07), and finally X4 (40/06) was used all files were used to full WL.

\section{Group III (ProTaper Gold System)}

The Files System were used in crown down manner using gentle in and out motion. The canals were instrumented to MAF \# F4/.06. The sequence of instrumentation was as following: Shaping files: S1 (18/0.02) (shaping file \# 1) was used to $3 / 4$ of W.L then, to full WL (speed: $300 \mathrm{Rpm}$ and torque: $3.0 \mathrm{Ncm})$. S2 (20/0.04) (shaping file \#2) was used to 3/4 of W.L then, to full WL (speed: 300 Rpm and torque: $1.0 \mathrm{Ncm}$ ). Shaping Files used with a brushing action on the withdrawal stroke. Finishing files: (F1 (size 20/taper 0.07), F2 (25/0.08), F3 (30/0.09), and F4 (40/0.06)) were used sequentially to full WL., the finishing files were used with non-brushing motions (pecking motions) until reaching the full WL (speed: 300 Rpm and torque: 2.0 Ncm except F1 used with $1.5 \mathrm{Ncm}$ ).

\section{Group IV (RECIPROC Blue System)}

R40/0.06 RECIPROC blue was inserted into the canal with a slow in-and-out pecking motion. The amplitude of the in- and out- movements (pecks) should not exceed 3-4 mm. Only very light pressure should be applied. The instrument will advance easily in the canal in an apical direction. After 3 pecks, or if resistance was encountered before the 3 pecks were completed, the instrument was removed and reused in the same manner until full WL had been reached. All the samples were instrumented by one operator (the researcher).

Irrigation was performed using 27-gauge endodontic needle. The depth of needle penetration into the canal was determined by introducing the needle passively into the canal to $2 \mathrm{~mm}$ short of the WL without any binding of the needle to the canal wall. After each instrument size (rotary instruments) or after three pecking motion (reciprocating instruments), the file was removed from the canal and the root canal was irrigated with $1 \mathrm{ml}$ of $1 \%$ of $\mathrm{NaOCl}$ irrigation, recapitulated with size $15 \mathrm{~K}$ file (Dentsply) and re-irrigated with $1 \mathrm{~mL}$ of $\mathrm{NaOCl}$. For standardization, each canal was irrigated with total amount $12 \mathrm{~mL}$ of $1 \%$ of $\mathrm{NaOCl}$. All files were cleaned periodically to prevent clogging of flutes during instrumentation with ethyl alcohol socked gauze pad before each entrance of the file into the canal. When the instrumentation was completed, $5 \mathrm{~mL}$ of distilled water were used as a final flush to remove the remnant debris and irrigating solutions inside the canal.

Each root sample was sectioned horizontally perpendicular to the long axis at $2 \mathrm{~mm}, 4.5 \mathrm{~mm}$ and $7 \mathrm{~mm}$ respectively from the apex with a low-speed saw under water cooling.

\section{Observation and Data Collection}

Each root section was examined under Stereomicroscope (MEIJI Techno, Japan) at magnification 25X. The presence of dentinal defects was determined by photographing all samples with a camera (Nikon, Japan). The number and the type of dentinal defects were recorded and classified using the following classification:

- No defect: No lines/cracks present in dentine (the slice has no defect at all) Figure 1.

- Incomplete crack: A line extended from inner root canal wall into the dentine without extending to the outer surface of root Figure 2.

- Complete crack: Presence of a line extending from inner root canal wall to outer surface of the root.

- Craze lines: A line that did not reach any surface of the root Graph 1.

\section{Statistical Analysis}

All statistical analyses was performed by statistical package for the social sciences (SPSS) software version 20 (USA). Data that represents the number and the type of dentinal defects were tabulated and analyzed using Fisher's exact test which performed to determine whether there is a statistical difference in the appearance
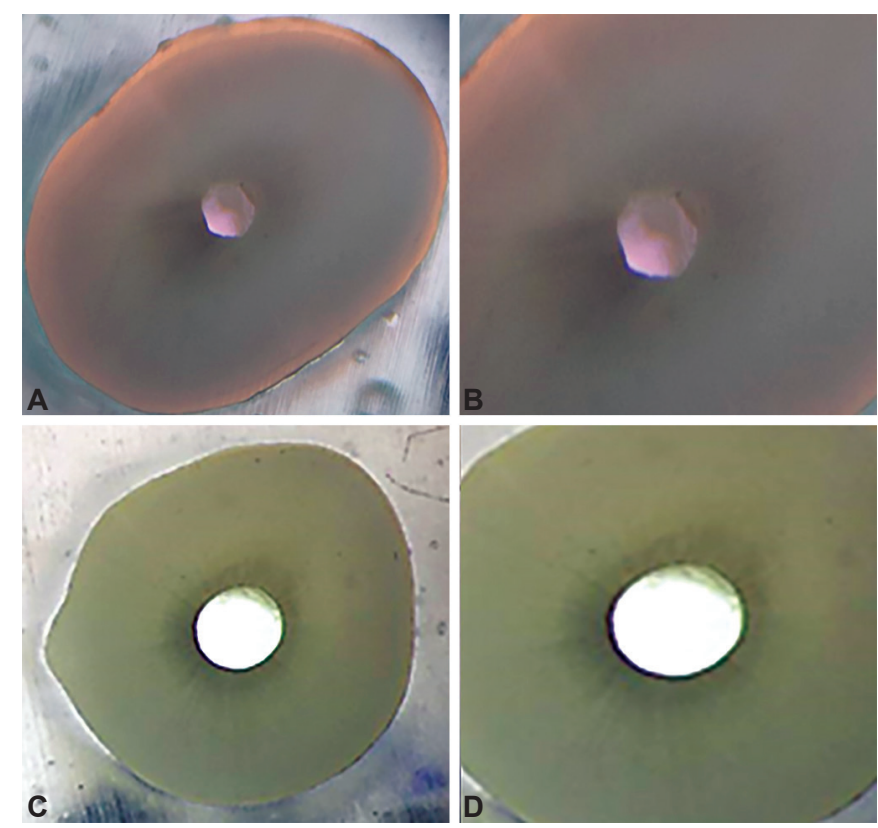

Figs 1A and D: Representative stereomicroscopic images for the root Cross sections at the apical level: (A and B) No dentinal defect (control group); (C and D) No dentinal defect after instrumentation 


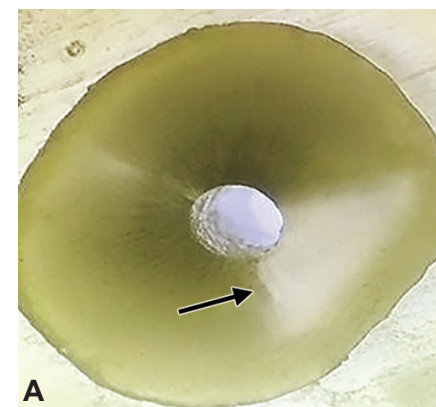

A
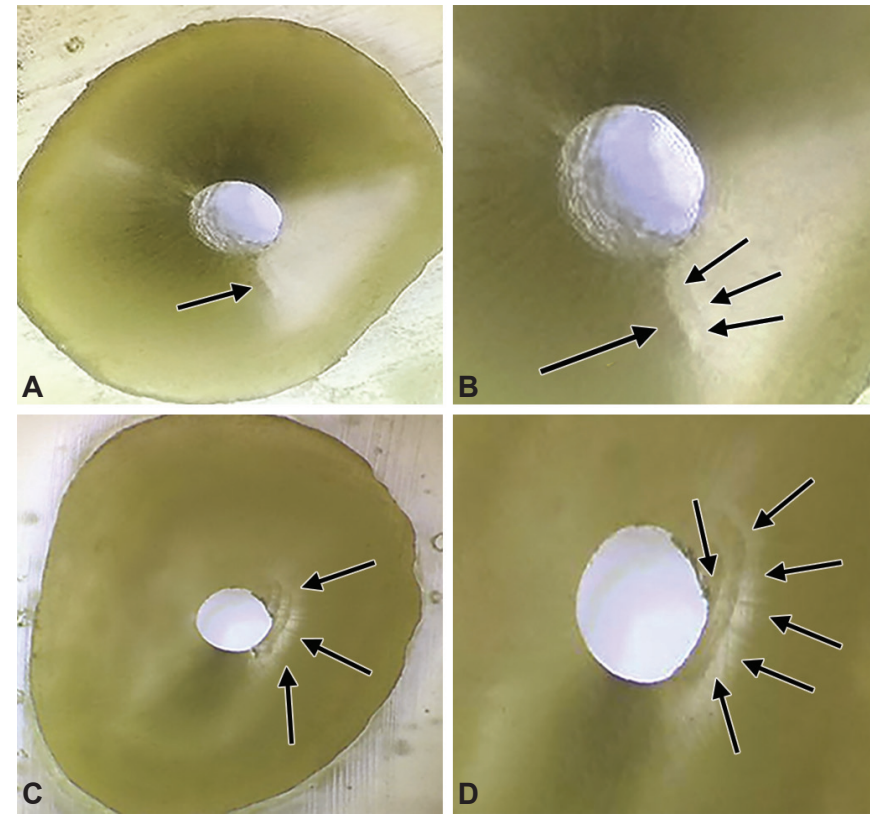

Figs 2A to D: Representative stereomicroscopic images for the root Cross sections at the apical level: (A and $B$ ) incomplete crack after instrumentation; ( $C$ and $D)$ Craze lines after instrumentation

of defected roots among the groups. Also, Fisher's exact test was performed among different groups at each level (apical, middle, or coronal). The level of significance was set at $p$ values 0.05 .

\section{RESULTS}

The distribution of dentinal defects per group and level are shown in Table 1. According to the collected data in this study, the RECIPROC group had the highest number of defected roots $(9 / 15)$, followed by ProTaper NEXT group (4/15), ProTaper Gold group (3/15) while the lowest number of defected roots were shown in the RECIPROC blue group (2/15), Graph 1 . Fisher's exact test showed that there were statistically significant differences among groups $(p \leq 0.05)$. The RECIPROC group showed a significant difference with the ProTaper Gold group $(p \leq 0.05)$ and significant difference with RECIPROC blue groups $(p \leq 0.01)$. Other comparison between each pair of other groups showed a non-significant difference $(p>0.05)$. Furthermore, Fisher's exact test was performed to identify the presence of any statistically significant difference among different groups at each level (apical, middle, coronal).

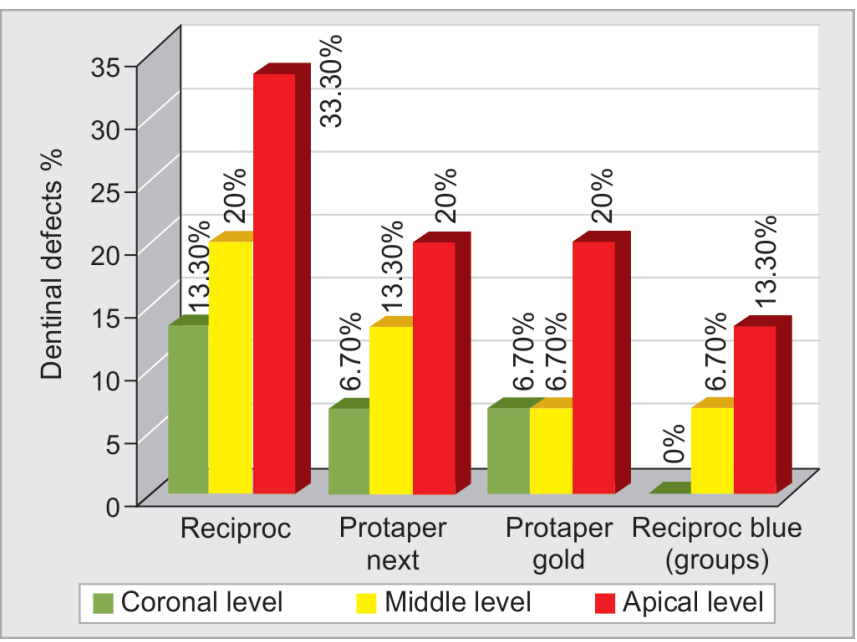

Graph 1: Percentages of dentinal defects at each level for all groups

A non-significant difference was found among the different groups (RECIPROC , ProTaper NEXT, ProTaper Gold and the RECIPROC blue) in the apical level and the same for the middle and the coronal levels $(p>0.05)$ or when comparing among different groups at the same level $(p>0.05)$. The Number and percentage of dentinal defects in all sections in each group $(\mathrm{N}=45)$ are shown in Table 2. From Table 2, the RECIPROC blue group had the lowest percentage 6.7\% followed by ProTaper Gold group 11.1\%, then the ProTaper NEXT group $13.3 \%$. The REC group $22.2 \%$.

\section{DISCUSSION}

During NiTi rotary instrumentation, rotational forces are applied on walls of the root canal and the canal shaped by the contact between NiTi instrument and dentinal walls. These contacts create numerous transitory stresses in the walls of the root canal. Higher stresses during rotary instrumentation can be expected to increase dentinal defects risks. In time, these dentinal defects are considered as stress concentrator and one of the secondary factors predisposing the tooth to vertical root fracture. ${ }^{11}$

Contact stress levels are determined by the mechanical behavior of files, which is determined by their cross sectional and longitudinal design. ${ }^{12,13}$ However, dentinal defects formation is complex. It is related not only to the design features of the file but also to its kinematics. ${ }^{14}$

Table 1: Number of dentinal defects at different levels and the number and percentage of roots with dentinal defects per group ( $N=15$ )

\begin{tabular}{llllll}
\hline Group & \multicolumn{3}{c}{ Number of microcracks roots with dentinal defects } \\
& Apical level $2 \mathrm{~mm}$ & Middle level $4.5 \mathrm{~mm}$ & Coronal level $7 \mathrm{~mm}$ & p value & Per group (\%) \\
\hline Control & Oa & 0 a & 0 a & $0^{\mathrm{a}}$ \\
RECIPROC & $5(33.3 \%)^{\mathrm{a}}$ & $3(20.0 \%)^{\mathrm{a}}$ & $2(13.3 \%)^{\mathrm{a}}$ & 0.550 & $9(60 \%)^{\mathrm{b}}$ \\
ProTaper NEXT & $3(20.0 \%)^{\mathrm{a}}$ & $2(13.3 \%)^{\mathrm{a}}$ & $1(6.7 \%)^{\mathrm{a}}$ & 0.857 & $4(26.7 \% 6)^{\mathrm{a}, \mathrm{b}}$ \\
ProTaper GOLD & $3(20.0 \%)^{\mathrm{a}}$ & $1(6.7 \%)^{\mathrm{a}}$ & $1(6.7 \%)^{\mathrm{a}}$ & 0.593 & $3(20.0 \%)^{\mathrm{a}}$ \\
RECIPROC blue & $2(13.3 \%)^{\mathrm{a}}$ & $1(6.7 \%)^{\mathrm{a}}$ & $0^{\mathrm{a}}$ & 0.762 & $2(13.3 \%)^{\mathrm{a}}$ \\
$p$ value & 0.694 & 0.820 & 0.896 & & 0.03 \\
\hline
\end{tabular}

Similar lowercase letters in the same column indicate no statistically significant differences $(p>0.05)$ 
Incidence of Dentinal Root Defects Caused by RECIPROC Blue, ProTaper Gold, ProTaper NEXT and RECIPROC

\begin{tabular}{|c|c|c|c|c|}
\hline & Incidence & Defect & No Defect & Total \\
\hline Group I & Number & 10 & 35 & 45 \\
\hline RECIPROC & Percentage & $22.2 \%$ & $77.8 \%$ & $100 \%$ \\
\hline Group II & Number & 6 & 39 & 45 \\
\hline ProTaper NEXT & Percentage & $13.3 \%$ & $86.7 \%$ & $100 \%$ \\
\hline Group III & Number & 5 & 40 & 45 \\
\hline ProTaper GOLD & Percentage & $11.1 \%$ & $88.9 \%$ & $100 \%$ \\
\hline Group IV & Number & 3 & 42 & 45 \\
\hline RECIPROC blue & Percentage & $6.7 \%$ & $93.3 \%$ & $100 \%$ \\
\hline
\end{tabular}

Moreover, the alloy from which the instrument was manufactured can be considered as an important factor in determining the dentin damaging potential of the file. Stiffer files generate higher stress concentration, which raises the risk of dentinal defects that may lead to root cracking. ${ }^{11}$ In addition, instrumentation involves removal of dentin that may compromise the strength of the roots. ${ }^{12}$ Resistance to tooth fracture is an important aim in endodontics because such fractures may decrease the long-term survival rate of the tooth. ${ }^{15}$

The mechanical response of a periodontal ligament to external stress is non-linear and viscous (viscoelastic), which is similar to the characteristics of elastomeric impression materials. ${ }^{16}$ For this reason, silicone impression material was used to hold the specimens in close environment during instrumentation to help in dispelling vertical applied force during canal preparation. ${ }^{17}$

In this study, all specimens were stored in hydrated environment all the time to prevent any dehydration in order to avoid any artefacts. ${ }^{18}$ The same apical size (\# 40) had been maintained for all instruments in the study for fair comparison between the different file systems.

Although the disadvantages associated with the methodology of root sectioning; however, there was no dentinal defect formation in the negative controlgroup. This would imply that the sectioning method in this study did not induce dentinal defects.

Under the condition of the present study, dentinal defects occurred regardless of the type of instruments used. This finding is in accordance with previous studies. ${ }^{19-22}$ In the present study, the incidence of defected roots in RECIPROC blue was found to be $(2 / 15)$, with a statistically significant difference with RECIPROC group. The reason behind this result due to the fact that although RECIPROC blue is a reciprocating file that can prepare canals with only single instrument with geometrical design that is identical to RECIPROC file, both have $\mathrm{S}$ shape cross-section design with two cutting edges and identical taper which are fixed at the apical $3 \mathrm{~mm}$ then the file has regressive taper. ${ }^{23}$

However, RECIPROC blue had been manufactured from blue NiTi alloy unlike RECIPROC instruments that manufactured using M-Wire NiTi alloy. Blue NiTi alloy obtained through a proprietary thermo-mechanical process that showed overall improved performances when compared with conventional M-Wire and superelastic NiTi alloy, demonstrating improved flexibility, reduced microhardness and produces a NiTi alloy that is softer and more ductile than the conventional one. ${ }^{9}$ Highly flexible endodontic instruments were associated with fewer dentinal defects since high flexibility of the alloy generates not only less stresses on the root canal walls but also less pressure on the instrument is required during instrumentation. ${ }^{11}$ This finding comes in line with Pedullà et al., who found less incidence of dentinal defects using NiTi instruments with increased flexibility than other experimental groups used..$^{19}$

ProTaper Gold showed (3/15) number of roots with dentinal defects, ProTaper Gold fileshave been manufactured using advanced metallurgy, the metallurgical characteristics of PTG files had high austenite finish temperature similar to controlled memory (CM) wire. In addition, ProTaper Gold had a 2-stage specific transformation behavior. These metallurgical characteristics give the files their greater flexibility. ${ }^{7}$ Karataş et al. found that the incidence of dentinal defects using ProTaper Gold was (9\%) which comes close to the percentage of the present study that showed (11.1\%). However, the difference could be explained by the fact that Karataş et al used different instrument size (MAF: F2) ${ }^{20}$ In contrast, Bayram et al found that new dentinal defects were not detected after preparation with ProTaper Gold. This could be attributed to the fact that Bayram et al use of different instrument size (MAF: F2), teeth (mandibular premolars) and different methodology. ${ }^{24}$

The incidence of defected roots in the ProTaper NEXT group was (4/15). This finding comes in line with Capar etal. ${ }^{21}$ and with Shori et al. both studies showed (4/15) incidence of dentinal defects in the ProTaper NEXT group. ${ }^{25}$ ProTaper NEXT showed a non-significant difference when compared with other groups. ProTaper NEXT files manufactured using $M$ wire with off-centered rectangular cross-section design. This design minimizing stresses and contact between the file and dentin. ${ }^{26}$ At any given time only two points of the file's cross section will make contact with the root canal wall. ${ }^{21}$ This may be the reason for decreasing damage in root canal. Another factor that reduced stress on dentine is 
the increased cross-sectional space that enhanced augering debris out of a canal compared to a file with a centered mass and axis of rotation, so less intra blade debris packed between the cutting flutes. ${ }^{27}$

RECIPROC group showed the highest number of defected roots (9/15). A probable explanation for this finding may be due to that RECIPROC is reciprocating file that can prepare canals with only single instrument. ${ }^{28}$ When root canals are shaped with only one single instrument, more stress is exerted upon the root canal wall by the instrument during mechanical instrumentation than using full-sequence rotary systems. The reason behind the generation of high stresses was the progression from small size/taper to larger size/taper which may be the cause behind the higher number of defects in RECIPROC group. ${ }^{29}$ The Reciprocation motion reduces the stress on the instrument but the stress on the dentine may still be high due to high amount of dentin removal using only single instrument. ${ }^{30}$

The cross section of RECIPROC file (S-shaped with sharp cutting edges) tend to remove more dentin than other instruments which show high amount of stress on dentin. ${ }^{31}$ Another cause may be that RECIPROC file manufactured using M-Wire that demonstrating less flexibility than its successor RECIPROC blue that show increased flexibility because it made from blue NiTi alloy that is softer and more ductile than $\mathrm{M}$ wire. ${ }^{9}$ As stiffer files generates greater stress concentrations that may increase the risk of dentinal defects. ${ }^{32}$ The stiffness of the file is related to the cross-section, size, taper, method of manufacturing, not only the alloy from which the instrument is manufactured. The alloy that the instrument manufactured is a more important factor determining the dentin damaging potential of single-file instruments than the motion of instrumentation. ${ }^{25}$

The development of dentinal defects in different levels of the root canal wall at the (apical, middle, or coronal) level showed no difference in the incidence of dentinal defects among all tested instrument.

According to these results it is reasonable to conclude that the synergistic effect of geometric features, flexibility NiTi alloy and kinematic may influence dentinal defects formation and the number of dentinal defects formation in each level. ${ }^{19}$ The taper of the files used for preparation could be a contributing factor to the formation of dentinal cracks. ${ }^{33}$ Both RECIPROC and RECIPROC blue instruments that has constant taper configuration at the apical $3 \mathrm{~mm}$ (0.06) followed by regressive taper, ${ }^{8}$ but the flexibility of the alloy used in RECIPROC blue resulted in less incidence of dentinal defects than RECIPROC as softer and increased flexibility files exerted less stress on the canal. ${ }^{19,32}$ PTG had a large apical taper of finishing files than other instruments (F1, F2, F3 and F4; 0.07, 0.08, 0.09 and 0.06 , respectively). However, the greater flexibility of instrument alloy which is similar to CM wire led to fewer incidence of dentinal defects. ${ }^{7,20}$ PTN (X1, X2, X3 and X4); had taper of $(0.04,0.06,0.07$ and 0.06$)$, respectively. ${ }^{27}$

In addition to the taper, the cross-section influences the behavior of the files in canal, which may result in different degree of dentinal defects as contact with root canal dentine occurs. ${ }^{16}$ Both RECIPROC and RECIPROC blue are single reciprocating files that have S-shaped cross-sectional design with sharp 2 cutting edges but with different metallurgy, ${ }^{9}$ and PTG (full-sequence rotary system) characterized by convex triangular cross section, ${ }^{20}$ whereas PTN (full-sequence rotary system have off-centered rectangular cross-section designs that make contact with dentin at only two points of the file at any given time. ${ }^{27}$

Moreover, the development of dentinal defects in different levels of the root canal wall may be influenced by the canal morphology, the narrow thickness of the canal in the apical area makes it more susceptible to crack formation because it has less ability to withstand the generated stresses during instrumentation. ${ }^{34,35}$ In addition, maximum stress concentration in apical third of root canals generated at the tip of instrument. ${ }^{35,36}$ For this reason the friction of the instruments with the root canal wall especially when larger stiffer files were used during instrumentation could be applied more pressure on the canal walls and attributed to cracking and fracture of the root canal walls. ${ }^{17}$

\section{CONCLUSIONS}

According to the proposed methodology and based on the findings of this in vitro study, the following conclusions could be drawn:

- All instrumentation systems that were used in this study cause dentinal defects.

- RECIPROC system resulted in increased incidence of defected roots compared to ProTaper Gold and RECIPROC blue systems.

- At the (apical, middle, or coronal) level: no difference in the incidence of dentinal defects among all tested instrument.

- No difference in the incidence of dentinal defects among all levels (apical, middle, or coronal) in each tested instrument.

\section{REFERENCES}

1. Haapasalo M, Shen, Y. Evolution of nickel-titanium instruments: from past to future. Endod Topics 2013;29(1):3-17.

2. Versiani MA, Souza E, De-Deus G. Critical appraisal of studies on dentinal radicular microcracks in endodontics: methodological issues, contemporary concepts, and future perspectives. Endod Topics 2015;33:87-156. 
3. Lertchirakarn V, Palamara J, Messer HH. Patterns of vertical fractures: factors affecting stress distribution in the root canal. J Endod 2003;29:523.

4. Hargreaves KM, Berman LH. Cohen's pathways of the pulp, 11th ed. St. Louis, Mosby Elsevier 2016:213.

5. Tsesis I, Rosen E, Tamse A, et al. Diagnosis of vertical root fractures in endodontically treated teeth based on clinical and radiographic indices:a systematic review. J Endod 2010,36(9):1455-1458.

6. Adorno CG, Yoshioka T, Suda H. Crack initiation on the apical root surface caused by three different nickel-titanium rotary files at different working lengths. J Endod 2011;37:522-525.

7. Hieawy A, Haapasalo M, Zhou H, et al. Phase transformation behavior and resistance to bending and cyclic fatigue of ProTaper Gold and ProTaper Universal Instruments. J Endod 2015;41:1134-1138.

8. Yared G. Canal preparation using one reciprocating instrument without prior hand filing: A new concept. International Dentistry - African edition 2012;2(2):78-87.

9. De-Deus G, Silva EJ, Vieira VT, et al. Blue Thermomechanical Treatment Optimizes Fatigue Resistance and Flexibility of the Reciproc Files. J Endod 2017;43(3):462-466.

10. Elnaghy AM. Cyclic fatigue resistance of ProTaper Next nickel-titanium rotary files. Int Endod J 2014;47(11):1034-1039.

11. El Nasr HMA, El Kader KGA. Dentinal damage and fracture resistance of oval roots prepared with single-file systems using different kinematics.J Endod 2014;40(6):849-851.

12. Kim HC, Lee MH, Yum J, et al. Potential relationship between design of nickel-titanium rotary instruments and vertical root fracture. J Endod 2010;36 (7):1195-1199.

13. Lam PP, Palamara JE, Messer HH. Fracture strength of tooth roots following canal preparation by hand and rotary instrumentation. J Endod 2005;31:529-532.

14. Dane A, Çapar ID, Arslan H. Effect of different torque settings on crack formation in root dentin. J Endod 2016;42:304-306.

15. Adorno CG, Yoshioka T, Jindan P, Kobayashi C, Suda H. The effect of endodontic procedures on apical crack initiation and propagation ex vivo. Int Endod J 2013;46:763-768.

16. Soares CJ, Pizi ECG, Fonseca RB, et al. Influence of root embedment material and periodontal ligament simulation on fracture resistance tests. Braz oral res 2005;19 (1):11-16.

17. Hin ES, Wu MK, Wesselink PR. Effects of self-adjusting file, Mtwo, and ProTaper on the root canal wall. J Endod. 2013;39:262-264.

18. Bürklein S, Tsotsis $P$, Schafer E. Incidence of dentinal defects after root canal preparation: reciprocating versus rotary instrumentation. J Endod 2013;39(4):501-504.

19. Pedullà E, Genovesi F, Rapisarda S, et al. Effects of 6 Single-File Systems on Dentinal Crack Formation. J Endod 2017;43(3):456-461.

20. Karataş E, Gündüz HA, Kırıcı DÖ, et al. Incidence of dentinal cracks after root canal preparation with ProTaper Gold, Profile Vortex, F360, Reciproc and ProTaper Universal instruments. Int Endod J 2015;12541.
21. Capar ID, Arslan H, Akcay M, et al. Effects of ProTaper Universal, ProTaper Next, and HyFlex instruments on crack formation in dentin. J Endod 2014:40:1482-1484.

22. Yoldas O, Yilmaz S, Atakan G. Dentinal microcrack formation during root canal preparations by different NiTi rotary instruments and the self-adjusting file.J Endod 2012;38:232-235.

23. Yared G. Reciproc blue: the new generation of reciprocation. Giornale Italiano di Endodonzia 2017;31,96-101.

24. Bayram HM, Bayram E, Ocak M, et al. Effect of ProTaper Gold, Self-Adjusting File, and XP-endo Shaper Instruments on Dentinal Microcrack Formation: A Micro-Computed Tomographic Study. J Endod 2017;43(7):1166-1169.

25. Shori DD, Shenoi PR, Baig AR, et al. Stereomicroscopic evaluation of dentinal defects induced by new rotary system: "ProTaper NEXT." J Conserv Dent 2015;18(3):210-213.

26. Ashraf F, Shankarappa P, Misra A, et al. A Stereomicroscopic Evaluation of Dentinal Cracks at Different Instrumentation Lengths by Using Different Rotary Files (ProTaper Universal, ProTaper Next, and HyFlex CM): An Ex Vivo Study. Scientifica 2016;837-865.

27. Ruddle CJ, Machtou P, West JD. The shaping movement: fifth-generation technology.Dent Today 2013;32(4):96-99.

28. Bürklein S, Hinschitza K, Dammaschke T, et al. Shapingability and cleaningeffectiveness of two single-file systems in severely curved root canals of extracted teeth: Reciproc and WaveOne versus Mtwo and ProTaper. Int Endod J 2012; 45(5):449-461.

29. LiSH, Lu Y, Song D, et al. Occurrence of dentinal microcracks in severely curved root canals with ProTaper Universal, WaveOne, and ProTaper ext file systems. J Endod 2015;41:1875-1879.

30. Logani A, Shah N. Apically extruded debris with three contemporary Ni-Ti instrumentation systems: An ex vivocomparative study. IJDR 2008;19(3):182-185.

31. Gergi R, Osta N, Bourbouze G, et al. Effects of three nickel titanium instrument systems on root canal geometry assessed by micro computed tomography. Int Endod J 2015;48(2):162-170.

32. Adl A, Sedigh-Shams M, Majd M. The effect of using RC Prep during root canal preparation on the incidence of dentinal defects. J Endod 2015;41(3):376-379.

33. Bier CA, Shemesh H, Tanomaru-Filho $\mathrm{M}$, et al. The ability of different nickel-titanium rotary instruments to induce dentinal damage during canal preparation. J Endod 2009;35(2):236-238.

34. Bernardes RA, Rocha EA, Duarte MAH, et al. Root canal area increase promoted by the EndoSequence and ProTaper systems: comparison by computed tomography.J Endod 2010;36(7):1179-1182.

35. Plotino G, Grande NM, Testarelli L, et al. Cyclic fatigue of Reciproc and WaveOne reciprocating instruments. J Endod 2012;45:614-618.

36. Medha A, Patil S, Hoshing U, et al. Evaluation of Forces Generated on Three Different Rotary File Systems in Apical Third of Root Canal using Finite Element Analysis. JCDR 2014;8(1):243-246. 